\title{
Partição do $P$ excretado nas fezes e urina de suínos em fase de crescimento, alimentados com dietas contendo diferentes níveis de enzima fitase
}

\author{
Partition of the P excreted in the faeces and urine of growing pigs, fed with diets \\ containing different levels of Phytase enzyme
}

\section{MOREIRA, José Aparecido ${ }^{1 *}$; SILVA, Apauliana Daniela Lima da ${ }^{1}$;OTA, Lorena Cunha ${ }^{1}$; SILVA FILHO, José Cleto da ${ }^{2}$; VITTI, Dorinha Miriam Silber Schmidt ${ }^{3}$}

\author{
${ }^{1}$ Universidade Federal do Rio Grande do Norte, Unidade Acadêmica Especializada em Ciências Agrárias, \\ Campus de Macaíba, Natal, Rio Grande do Norte, Brasil. \\ ${ }^{2}$ Universidade Federal de Lavras, Lavras, Minas Gerais, Brasil. \\ ${ }^{3}$ Universidade Federal de São Paulo, Centro de Energia Nuclear na Agricultura, Piracicaba, São Paulo, Brasil. \\ *Endereço para correspondência: japmoreira@bol.com.br
}

\section{RESUMO}

Este estudo teve como propósito avaliar a partição do $\mathrm{P}$ excretados nas fezes e urina de suínos em fase de crescimento, alimentados com dietas contendo diferentes níveis de inclusão de enzima fitase, através do uso do radioisótopo P32. Foram utilizados 20 suínos, machos castrados, em delineamento de blocos ao acaso, com cinco tratamentos $-0 ; 250 ; 500 ; 750$ e $1000 \mathrm{UF} / \mathrm{kg}$ da ração - e quatro repetições. Os animais foram alojados em gaiolas metabólicas por 17 dias, sendo dez dias para adaptação e sete dias para coleta de fezes e urina. Amostras de sangue foram coletadas por cinco dias. No primeiro dia da fase experimental, cada animal recebeu por via endovenosa uma solução radioativa com $7,4 \mathrm{MBq}$ de ${ }^{32} \mathrm{P}$. O uso de fitase em dietas para suínos proporciona redução do $\mathrm{P}$ total e solúvel excretados nas fezes. Pode-se reduzir em $50 \%$ a suplementação de $\mathrm{P}$ por fosfato bicálcico nas dietas para suínos em crescimento, adicionando 500UF/ $\mathrm{kg}$ de dieta, sem provocar prejuízos ao sistema físiológicos dos animais.

Palavras-chave: fitase, fósforo, nutrição, técnica de diluição isotópica

\section{SUMMARY}

This study had as purpose to evaluate the partition of $P$ excreted in the faeces and urine of growing pigs fed with diets containing different levels of inclusion of phytase enzyme, through the use of radioisotope P-32.). Twenty pigs crossbred barrows were evaluated in a randomized block design experiment, with five treatments, $0 ; 250 ; 500 ; 750$ and 1000PUkg diet, and four replicates. The animals were kept in metabolic cages for a 10-day adaptation period and seven days for total collection of feces and urine. Blood samples were taken for five days. On the first day of the collection period each animal was injected intravenously with $7.4 \mathrm{MBq}$ ${ }^{32} \mathrm{P}$ phytase. The use of Phytase in diets for pigs provides reduction of $\mathrm{P}$ total and soluble excreted in the feces. On diets for growing pigs containing corn and soybean meal, you can reduce by $50 \%$ of the supplementation of the dicalcium phosphates, adding 500UF/ $\mathrm{kg}$ diet, without causing damage to animal physiological system.

Keywords: isotopic dilution tecnique, phytase enzyme, phosphorus, nutrition 


\section{INTRODUÇÃO}

A nutrição animal constitui um dos pilares que garantem a lucratividade e sobrevivência dos suinocultores na atividade. Em tempos modernos e com o avanço no campo da genética $\mathrm{e}$ nutrição animal aplicada à suinocultura, está atividade atingiu um nível de tecnologia capaz de colocá-la entre as principais atividades no ramo da zootecnia (GONÇALVES \& PALMEIRAS, 2006). A maior lucratividade do setor pode ser obtida com a maximização da produtividade e redução dos custos, aliados a mitigação da poluição ambiental. Para proteger o ambiente é necessário estabelecer uma ação conjunta entre o sistema de tratamento de dejetos e o uso de dietas que atendam as reais necessidades fisiológicas dos animais (SANTOS et al., 2009).

$\mathrm{O}$ fósforo é um elemento químico que participa de todo processo bioquímico que envolve a vida do animal, presentes em reações como glicólise, ciclo de Krebs, ciclos das pentoses e fosforilação oxidativa, além de participar das moléculas dos ácidos nucleicos. Neste contexto, uma deficiência de $\mathrm{P}$ em períodos longos pode levar a perda da produtividade e da lucratividade do setor. No entanto, nos estágios iniciais da deficiência os ossos serão os primeiros órgãos a serem afetados (MOREIRA et al, 2009) e os animais estarão mais suceptíveis a fraturas ósseas.

Diversos autores apontam como alternativa viável o uso de fitase em dietas para suínos (LUDKE et al., 2002; SANTOS et al., 2008; WOYENGO et al., 2008; DIAS et al., 2010; AGUDELO et al., 2010) em fase de crescimento e terminação. A fitase não é sintetizada no trato digestivo dos suínos, sendo o uso da enzima uma solução viável para $\mathrm{o}$ aproveito do fósforo fitico, podendo reduzir o custo das dietas e o impacto ambiental provocado pelo $\mathrm{P}$ excretado nas fezes (SANTOS et al., 2008).

Há muitas técnicas convencionais para estudar os impactos deste elemento no metabolismo animal, entretanto, a técnica de digestibilidade aparente não é recomendada, pois desconsidera a fração endógena, que corresponde de 8 a $16 \%$ da excreção total (MOREIRA, et al., 2004; TEIXEIRA et al, 2004). Sendo assim, o uso de uma metodologia capaz de determinar a fração endógena é imprescindível.

A técnica de diluição isotópica se fundamenta no fato dos isótopos dos elementos radioativos e estáveis terem comportamentos similares no metabolismo animal, permitindo o estudo do fluxo do mineral e a quantificação da fração endógena (VITTI \& KEBREAB, 2010), neste contexto este trabalho tem como propósito avaliar a partição do fósforo excretado nas fezes e urina de suínos em fase de crescimento, alimentados com dietas contendo diversos níveis de inclusão da enzima fitase, através do uso do radioisótopo P-32.

\section{MATERIAL E MÉTODOS}

O experimento foi conduzido no Laboratório de Nutrição Animal do Centro de Energia Nuclear na Agricultura da Universidade de São Paulo, em Piracicaba - SP.

Foram utilizados 20 leitões mestiços, machos castrados, com peso médio de $26,8 \pm 5,04 \mathrm{~kg}$, alojados em gaiolas metabólicas, semelhantes às descritas por Pekas (1968). Os animais foram distribuídos em um delineamento em 
blocos casualizados, contendo 4 tratamentos e 5 repetições, sendo o peso utilizado como parâmetro para formação dos blocos. Os tratamentos consistiram dos níveis de enzima fitase (Quantun Phytase): 0; 250; 500; 750 e $1000 \mathrm{UF} / \mathrm{kg}$ de ração.

As rações experimentais foram compostas por milho e farelo de soja, contendo $14 \%$ de PB e $3250 \mathrm{kcal}$ de energia metabolizável, suplementadas com aminoácidos (L-lisina, DLmetionina, L-treonina e L- triptofano), minerais e vitaminas, para atender às exigências nutricionais de suínos na fase de crescimento, exceto em $\mathrm{P}$, seguindo as recomendações sugeridas por Rostagno et al. (2011). As dietas foram oferecidas aos animais de acordo com o consumo metabólico $\left(\mathrm{W}^{0,75}\right)$, sendo umedecidas na proporção de 1:1 água/ração.

As dietas foram compostas por $84,03 \%$ de milho, $13,50 \%$ de farelo de soja, $0,372 \%$ de fosfato bicálcico, $0,64 \%$ de calcário, 0,025 de premix vitamínico$41,0,025 \%$ de premix vitamínico-25, $0,10 \%$ de premix mineral, $0,51 \%$ de Llisina $(98,5 \%), 0,11 \%$ de DL-metionina $(99,5 \%), 0,18 \%$ de L-treonina $(98,5 \%)$ e $0,05 \%$ de L-triptofano $(98,5 \%)$, contendo: 0,$0 ; 0,01 ; 0,02 ; 0,03$ e $0,04 \%$ de enzima fitase, respectivamente.

As rações foram oferecidas aos animais em duas refeições diárias, às $7 \mathrm{~h} 30 \mathrm{~min} \mathrm{e}$ às $15 \mathrm{~h} 30 \mathrm{~min}$. Na fase de adaptação, os animais foram estimulados a consumirem o máximo de ração, e, na fase de coleta, visando evitar sobras, as quantidades de ração em cada tratamento foram baseadas no menor consumo dentre os animais do bloco, obtido no período pré- experimental (SAKOMURA \& ROSTAGNO, 2007).

A água foi oferecida à vontade. No primeiro dia da fase experimental, cada animal recebeu por via endovenosa, $0,5 \mathrm{~mL}$ de uma solução radioativa com
$7,4 \mathrm{MBq}$ de ${ }^{32} \mathrm{P}$. A solução radioativa, preparada de acordo com Vitti et al. (2006), era constituída de fosfato de sódio $\left(\mathrm{Na}_{2} \mathrm{H}^{32} \mathrm{PO}_{4}\right)$, livre de carregador e adquirida no Instituto de Pesquisas Energéticas (IPEN). Após a aplicação do material radioativo, foram coletados diariamente, durante sete dias, $10 \mathrm{~mL}$ de sangue, com o uso de tubos a vácuo heparinizados, em intervalos de 24 horas.

As amostras de sangue foram centrifugadas imediatamente após a coleta em $3000 \mathrm{rpm}$, durante 10 minutos, e o plasma separado.

Para a detecção da radioatividade, $0,5 \mathrm{~mL}$ de plasma foi adicionado em água deionizada em frasco de contagem e a determinação foi obtida por efeito Cerenkov (IAEA, 1979; NASCIMENTO FILHO \& LOBÃO, 1977). Ao volume de $1 \mathrm{~mL}$ de plasma adicionou-se $9 \mathrm{~mL}$ de ácido tricloroacético a $10 \%$, e o teor de $\mathrm{P}$ inorgânico determinado por colorimetria.

As fezes foram coletadas durante sete dias, pesadas, maceradas e homogeneizadas e, para determinação da radioatividade, foi colocado um grama em cadinhos de porcelana para as determinações da matéria seca $\left(100^{\circ} \mathrm{C}\right)$ e das cinzas $\left(500^{\circ} \mathrm{C}\right)$. As cinzas foram digeridas com $10 \mathrm{~mL}$ de ácido sulfúrico $(18 \mathrm{~N})$ e o material digerido colocado em frascos de cintilação, completandose o volume para $20 \mathrm{~mL}$ com água destilada, determinando-se a radioatividade por efeito Cerenkov (VITTI et al., 2006).

Para determinação do $\mathrm{P}$ total, cerca de $1 \mathrm{~g}$ de fezes foi digerido com $5 \mathrm{~mL}$ de ácido clorídrico concentrado, seguindo-se filtragem e, ao volume de $2,5 \mathrm{~mL}$ do filtrado foram adicionados $2,5 \mathrm{~mL}$ de água deionizada e $2 \mathrm{~mL}$ de reagente misto (quantidades iguais de molibdato 
de amônia a 5\% e vanadato de amônia a $0,25 \%$ (SARRUGE \& HAAG, 1974).

A urina foi coletada diariamente, sendo uma alígota de 10\% armazenada em freezer. $O$ fósforo inorgânico foi determinado após a diluição de $1 \mathrm{~mL}$ de urina em $9 \mathrm{~mL}$ de ácido tricloroacético (10\%). Para a determinação da radioatividade foram diluídos $0,5 \mathrm{~mL}$ de urina em $19,5 \mathrm{~mL}$ de água deionizada, e a atividade determinada pelo efeito Cerenkov (VITTI et al. 2006).

As análises bromatológicas das dietas foram realizadas segundo as recomendações da AOAC (1980). A atividade do radionuclídeo foi determinada por efeito Cerenkov, em espectrômetro de cintilação líquida (NASCIMENTO FILHO \& LOBÃO, 1977). O teor de $P$ nas dietas foi calculado pelo método do vanado molibdato (SARRUGE \& HAAG, 1974). A porcentagem da atividade injetada e as atividades específicas encontradas no plasma e nas fezes foram efetuadas conforme Lofgreen (1960), e o valor do P endógeno baseado em Vitti et al. (2006).

$$
\begin{aligned}
& \begin{array}{l}
\% \text { da atividade injetada } \\
\text { encontrada no plasma }
\end{array} \\
& \text { contagem por minuto da solução padrão }
\end{aligned}
$$$$
\begin{aligned}
& \% \text { da atividade injetada } \\
& \text { encontrada nas fezes }
\end{aligned}=\frac{\text { contagem por minuto }(1 \mathrm{~g} \text { de fezes })}{\text { contagem por minuto da solução padrão }} \times 100
$$$$
\text { Atividade específica nas fezes }=\frac{\% \text { atividade injetada }}{(\text { mo tempot }+24 \text { horas) }}
$$$$
\text { (no tempo } \mathrm{t}+24 \text { horas) } \quad \mathrm{mg} \mathrm{P} / \mathrm{g} \text { de fezes }
$$$$
\% \mathrm{P} \text { endógeno }=\frac{\text { atividade específica fezes }}{\text { atividade específica plasma }} \times 100
$$

$\mathrm{P}$ endógeno total nas fezes $=\%$ de $\mathrm{P}$ endógeno $\mathrm{X} \mathrm{P}$ total excretado nas fezes $\mathrm{P}$

Absorção real $=\mathrm{P}$ consumido $-(\mathrm{P}$ excretado nas fezes $-\mathrm{P}$ endógeno

A concentração de fitato nos alimentos, nas rações e nas fezes foi determinada segundo metodologia descrita por Latta \& Eski (1980), com adaptações sugeridas por Frühbeck et al. (1995). A conversão da concentração de fitato em $\mathrm{P}$ fítico foi calculada considerando-se que a proporção molar do $\mathrm{P}$ na molécula de fitato é de 28,2\% (ANGEL et al., 2002).
O P solúvel nas fezes foi obtido pela diferença entre o $\mathrm{P}$ total e a somatória do $\mathrm{P}$ endógena e o teor de fitato.

As variáveis avaliadas foram submetidas à análise da variância segundo o modelo estatístico: $\mathrm{Y}_{\mathrm{ij}}=\mathrm{m}+\mathrm{N}_{\mathrm{i}}+\mathrm{B}_{\mathrm{j}}+\mathrm{e}_{\mathrm{ij}}$;

Em que $\mathrm{Y}_{\mathrm{ij}}=$ variáveis observadas; $\mathrm{m}=$ média geral; $\mathrm{N}_{\mathrm{i}}=$ efeito da inclusão de enzima fitase nas dietas $\mathrm{i}(\mathrm{i}=0 ; 250$; 
$500 ; 750$ e 1000UF); $\mathrm{B}_{\mathrm{j}}=$ efeito de bloco j (1;2; 3; e, 4); $\mathrm{E}_{\mathrm{ij}}=$ erro aleatório associado a cada observação.

Os graus de liberdade referentes aos níveis da enzima foram desdobrados em polinômios ortogonais, para obtenção das equações de regressão. Como ferramenta de análise estatística utilizou-se os procedimentos do SAS Institute (2002).

\section{RESULTADOS E DISCUSSÃO}

A suplementação de dietas para suínos em crescimento com enzima fitase não interferiu no consumo de ração, de $\mathrm{P}$ total e de $\mathrm{P}$ fítico, resultado esperado em função do uso do consumo metabólico $\left(\mathrm{kg}^{0,75}\right)$ (TEIXEIRA et al,. 2004, LOPES et al., 2009) como parâmetro para desenvolver o estudo (Tabela 2).

Tabela 2. Efeito dos níveis crescentes de enzima fitase (UF/kg) na dieta sobre os parâmetros relacionados a partição de $\mathrm{P}$ em dejetos de suínos

\begin{tabular}{|c|c|c|c|c|c|c|c|}
\hline \multirow{2}{*}{$\begin{array}{l}\text { Parâmetros estudados } \\
\text { (g/kg/PV/dia) }\end{array}$} & \multicolumn{7}{|c|}{ Níveis de inclusão de fitase (UF/kg dieta) } \\
\hline & 0 & 250 & 500 & 750 & 1000 & ${ }^{2} \mathrm{CV}(\%)$ & ${ }^{3} \mathrm{P}$ \\
\hline Consumo de ração & 41,88 & 41,92 & 41,85 & 41,39 & 41,77 & 10,81 & 0,92 \\
\hline $\mathrm{P}$ total consumido & 3,88 & 4,11 & 3,81 & 3,94 & 3,81 & 4,92 & 0,21 \\
\hline Acido fítico consumido & 2,93 & 3,03 & 2,74 & 2,94 & 2,85 & 4,83 & 0,11 \\
\hline$P$ total excretado ${ }^{1}$ fezes* & 2,13 & 1,94 & 1,55 & 1,65 & 1,51 & 24,47 & 0,04 \\
\hline P total absorvido & 1,93 & 2,45 & 2,46 & 2,51 & 2,49 & 17,26 & 0,29 \\
\hline $\mathrm{P}$ solúvel excretado ${ }^{1}$ & 1,92 & 1,61 & 1,30 & 1,40 & 1,28 & 30,12 & 0,05 \\
\hline $\mathrm{P}$ endógeno & 0,18 & 0,27 & 0,21 & 0,21 & 0,18 & 45,14 & 0,66 \\
\hline $\mathrm{P}$ urina & 0,03 & 0,04 & 0,02 & 0,01 & 0,03 & 57,52 & 0,06 \\
\hline Fitato excretado & 0,03 & 0,06 & 0,04 & 0,04 & 0,04 & 44,30 & 0,33 \\
\hline $\mathrm{P}$ absorvido real & 1,93 & 2,45 & 2,46 & 2,51 & 2,49 & 17,26 & 0,29 \\
\hline $\mathrm{P}$ retido & 1,90 & 2,41 & 2,44 & 2,50 & 2,46 & 17,46 & 0,27 \\
\hline
\end{tabular}

${ }^{1}$ Efeito linear $(\mathrm{P}<0,05),{ }^{2}$ Coeficiente de variação, ${ }^{3}$ Probabilidade.

Para avaliar os impactos do uso da fitase sobre a excreção de $\mathrm{P}$ nas fezes, analisou-se a relação entre os níveis de fitase $(\mathrm{X})$ e o $\mathrm{P}$ Total excretado fezes (Y), em que $\hat{Y}=2,061-0,0006 x, R^{2}=$ 0,21 (Figura 1), obtendo-se um efeito linear, onde a excreção do $\mathrm{P}$ nas fezes foi reduzida progressivamente. A fitase foi eficiente em realizar o catabolismo do complexo inositol-fosfato disponibilizando o $\mathrm{P}$ para $\mathrm{o}$ metabolismo animal, corroborando com diversos autores (LUDKE et al. 2002, DIAS et al. 2010) que também obtiveram respostas similares. $\mathrm{O}$ uso de dietas suplementadas com fitase além de reduzir a excreção $\mathrm{P}$ fezes pode reduzir o custo das dietas (SANTOS, 2009), pois permite balancear dietas com baixos níveis de fósforo.

$\mathrm{O}$ uso de formulação de rações com alimentos contendo altos teores de $\mathrm{P}$ total, como o farelo de arroz desengordurado, permite uma redução em $100 \%$ do uso de fosfato bicálcico nas dietas, sem afetar o desempenho (MOREIRA et al., 2004) e as características fisiológicas dos animais (MOREIRA et al., 2009). 


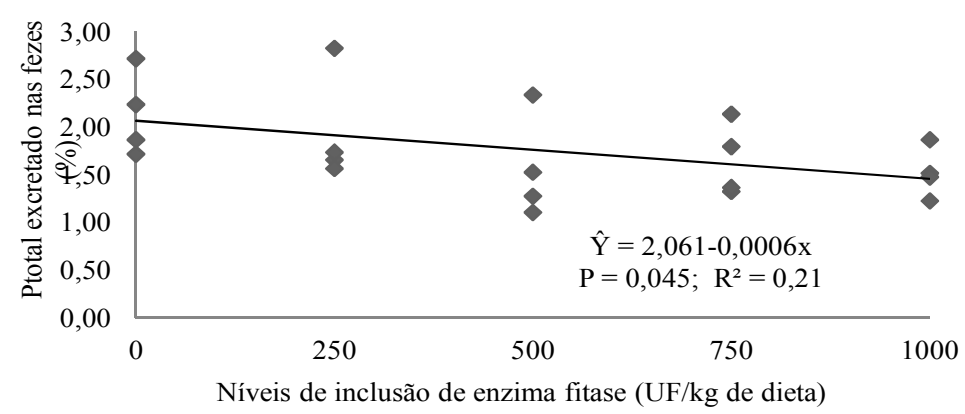

Figura 1. Efeito dos níveis de enzima fitase (UF/kg de dieta)

O P solúvel excretado nas fezes representa a fração do $\mathrm{P}$ disponível para ser utilizados pelas plantas aquáticas, sendo considerado o elemento mais poluente. $\mathrm{O}$ estudo da relação entre os níveis de fitase $(\mathrm{X})$ e o $\mathrm{P}$ o solúvel excretado nas fezes (Y), em que
$\hat{\mathrm{Y}}=1,801-0,0006 \mathrm{x}, \mathrm{R}^{2}=0,20$ (Figura 2), revelou um efeito linear negativo, comportamento similar ao observado na avaliação do $\mathrm{P}$ total, demonstrando que fitase foi eficiente em reduzir $O$ potencial poluente das excretas.

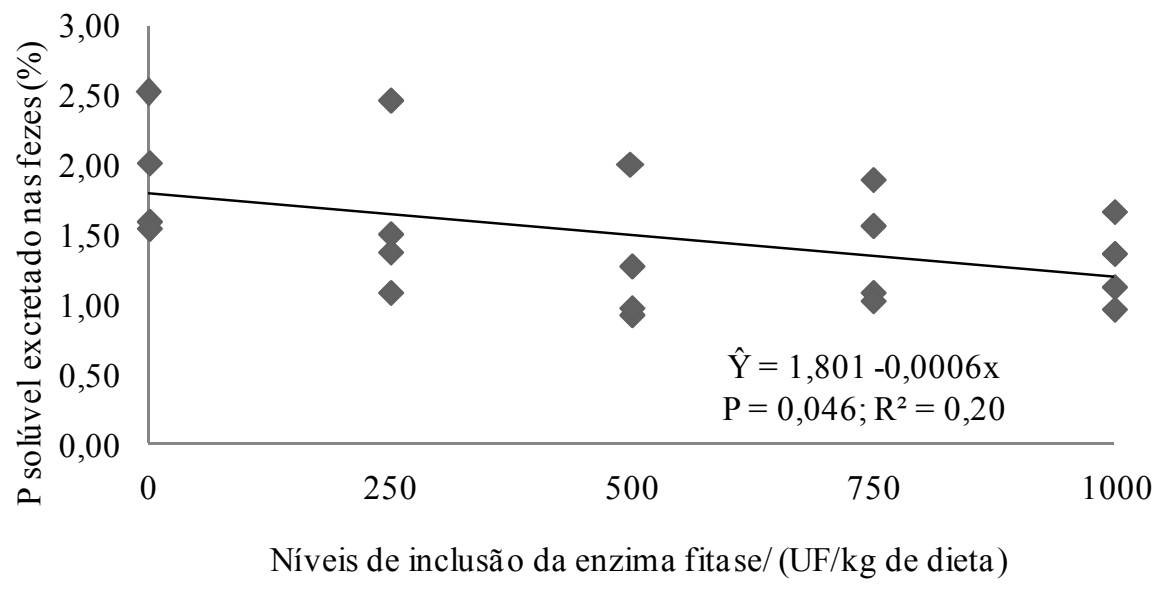

Figura 2. Efeito dos níveis da enzima fitase sobre o P solúvel excretado nas fezes

A redução do $\mathrm{P}$ solúvel observado neste experimento difere dos resultados obtidos por Miles et al. (2003) que constaram aumento no $\mathrm{P}$ solúvel em excretas de frango de corte alimentados com dietas suplementadas com fitase. Os resultados obtidos neste experimento comprovam que as dietas atenderam as necessidades nutricionais dos animais, sendo as perdas de $\mathrm{P}$ total e solúvel reduzidas.

Os impactos provocados pelo $\mathrm{P}$ no ambiente estão condicionados ao manejo inadequado dos dejetos. 
Quando o P é lixiviado e atinge o lençol freático ou quando chega até os rios desencadeia a eutrofização (SHARPLEY, 1999), provocando a mortalidade de organismos aquáticos.

$\mathrm{Na}$ avaliação bioquímica do $\mathrm{P}$ encontram-se três tipos de moléculas: $\mathrm{O}$ fitato, a fitina e o ácido fítico. $O$ fitato se refere ao sal misto do ácido fítico (myo- inositol-hexafosfato), a fitina representa o complexo myo-inositol hexafosfato com potássio, magnésio e cálcio e o ácido fitico é a forma livre do myo-inositol hexafosfato (SELLE \& RAVINDRAM, 2007). A fitina presente em ingredientes vegetais é solubilizada em $\mathrm{pH}$ ácido no início do trato gastrointestinal de suínos, passando para a sua forma livre, a ácido fítico (SANTOS, 2009). No duodeno o ácido fítico é alcalinizado através de excreções dos sulcos pancreáticos e forma quelatos com minerais $\mathrm{e}$ aminoácidos formando a molécula de fitato.

Os animais monogástricos como os suínos não sintetizam a enzima fitase, sendo assim, a única maneira de se aproveitar o $\mathrm{P}$ e outros nutrientes presentes nos cereais é pelo uso de dietas suplementadas com fitase (JONGBLOED et al., 2013). Neste contexto, para se conhecer o potencial de metabolização do $\mathrm{P}$ proveniente da dieta no metabolismo de suínos avaliouse as rotas de excreção do P. As excreções endógenas e urinárias se constituem entre as principais portas de saídas para a excreção do excesso de $\mathrm{P}$, sendo a rota endógena a mais importante. Foi obtido neste experimento uma perda de 9 a $14 \%$ de $\mathrm{P}$ via endógena e 1,5 a $3,00 \%$ via urinária, representando valores próximos aos obtidos por Moreira et al. (2004) e Teixeira et al. (2004), entretanto, não se observou efeito da enzima sobre estas variáveis $(\mathrm{P}$ $>0,05)$, sendo a mesma constatação feita para o $\mathrm{P}$ total absorvido, $\mathrm{P}$ real absorvido e a excreção de fitato nas fezes. Estes resultados representam o reflexo do balanceamento das dietas com baixos níveis de $\mathrm{P}$ total e a eficiência da enzima em disponibilizar o $P$ para ser utilizado no metabolismo animal.

O uso de fitase em dietas para suínos proporciona redução do $\mathrm{P}$ total e solúvel excretado nas fezes. Pode-se reduzir em $50 \%$ a suplementação de $\mathrm{P}$ por fosfato bicálcico nas dietas para suínos em crescimento, adicionando $500 \mathrm{UF} / \mathrm{kg}$ de dieta, sem provocar prejuízos ao sistema fisiológicos dos animais.

\section{AGRADECIMENTOS}

À Fundação de Amparo à Pesquisa do Estado de São Paulo (FAPESP) pelo financiamento do projeto e as empresas ABVista Feed Ingredients, Nutron e Ajinomoto pela doação de ingredientes.

\section{REFERÊNCIAS}

AGUDELO, J.H.; LINDERNANN, M.D.; CROMWEL, G.L. Phosphorus utilization in growing pigs fed a phosphorus dieficient diet supplement a rice bran product amended phytase.

\section{Revista Colombiana de Ciências}

Pecuária, v.23, p.429-443, 2010.

ANGEL, R.; TAMIM, N.M.; APPLEGATE, T.J.; DHANDU, A.S.; ELLESTAD, L.E. Phytic acid chemistry: influence on phytinphosphorus availability and phytase efficacy. Journal of Applied Poultry Research, v.11, n.4, p.471-480, 2002. 
ASSOCIATION OF OFFICIAL

ANALYTICAL CHEMISTS - AOAC.

Official methods of analysis. 13.ed.

Washington: AOAC, 1980. 1018p.

DIAS, R.S.; LOPEZ, S.; MOREIRA, J.A.; LOPEZ, S.; FRANCES, J.

Application of a kinetic model to describe phosphorus metabolism in pig fed a diets with a microbial phytase.

Journal Agriculture Science, v.148, p.277-286, 2010.

FRÜHBECK, G.; ALONSO, R.; MARZO, F.; SANTIDRIÁN, S. A modified method for the indirect quantitative analysis of phytate in foodstuffs. Analytical Biochemistry, v.225, n.2, p. 206-212, 1995.

GONÇALVES, R.G.; PALMEIRAS,

E.M. Suinocultura brasileira.

Observatório de la Economia

Latinoamericana, n.71, p.01-11, 2006.

INTERNATIONAL ATOMIC ENERGY AGENCY - IAEA.

Laboratory training manual on the use of nuclear techniques in animal research. Vienna: IAEA, 1979. 299p. (Technical Report Series, 193).

JONGBLOED, A.W.; DIEPEN, J.TH.M.V.; BINNENDIJK, G.P.; BIKKER P., VEREECKEN M.; BIERMAN K. Efficacy of OptiphosTM phytase on mineral digestibility in diets for breeding sows: effect during pregnancy and lactation. Journal of Livestock Science, v.4, p.7-16, 2013.

LATTA, M.; ESKIN, M. A simple and rapid colorimetric method for phytate determination. Journal of Agricultural and Food Chemistry, v.28, n.6, p.1313-1315, 1980.
LOPES, J.B.; KEBREAB, E; VITTI, D.M.S.S.; MOREIRA, J.A.;

ABDALLA, A.L.; CROMPTON, L.A.; FRANCES, J. A model on biological flow of phosphorus in growing pigs. Arquivo Brasileiro de Medicina Veterinária e Zootecnia, v.61, p.691697, 2009.

LOFGREEN, G.P. The availability of the phosphorus in dicalcium phosphate, bone meal, soft phosphate and calcium phytate for madure wether. Journa

Nutrition., v.70, p.58-62, 1960.

LUDKE, M. do C.M.M.; LOPEZ, J.; LUDKE, J.V. Fitase em dietas para suínos em crescimento: (i) impacto ambiental. Ciência Rural, v.32, p.97102, 2002.

MILES, D.M.; MOORE JUNIOR, P.A.; SMITH, D.R.; RICE, D.W.; STILBORN, H.L.; ROWE, D.R.; LOTT, B.D.; BRANTON, S.L.; SIMMONS, J.D. Total end water soluble phosphorus in broiler litter over three flocks with alum litter treatment in diets inclusions high available phosphorus corn and phytase supplementation. Poultry Science, v.82, p.1544-1549, 2003.

MOREIRA, J.A.; VITTI, D.M.S.S.; LOPES, J.B.; TRINDADE NETO, M.A. Fluxo biológico do fósforo no metabolismo de suínos alimentados com dietas contendo fitase. Revista Brasileira de Zootecnia, v.33, p.20662075, 2004.

MOREIRA, J.A.; VITTI, D.M.S.S.; TEIXEIRA, A.O.; LOPES, J.B. Fisiologia digestiva de suínos alimentados com rações contendo diferentes fontes de fósforo. Revista Brasileira de Zootecnia, v.38, p.676678, 2009. 
NASCIMENTO FILHO, V.F.;

LOBÃO, A.O. Detecção de P-32 em amostras de origem animal e vegetal por efeito cerenkov, cintilação líquida e detector GM. Piracicaba: CENA, 1977. 25p. (Boletim Científico, 48).

PEKAS, J.C. Versatile swine laboratory apparatus for physiologic and metabolic studies. Journal of Animal Science, v.27, n.5. p.1303-1309, 1968.

ROSTAGNO, H.S.; ALBINO, L.F.T.; DONZELE J.L.; GOMES, P.C; OLIVEIRA, R.F.; LOPES, D.C.; FERREIRA, A.S.; BARRETO, S.L.T.; EUCLIDES, R.F. Composição de alimentos e exigências nutricionais: tabelas brasileiras para aves e suínos. 3.ed. Viçosa: UFV, 2011. 252 p.

SAKOMURA, N.K., ROSTAGNO, R.S. Métodos de pesquisa em nutrição de monogástrico. Jaboticabal: FUNEP, 2007, 283p.

SARRUGE, J.R.; HAAG, H.P. Análises químicas em plantas. Piracicaba: ESALQ/USP, 1974. 56p.

SHARPLEY, A. Agricultural phosphorus, water quality e poultry production, area day compatible.

Poultry Science, v.78, p.660 - 673, 1999.

SANTOS, S.P.; NUNES, R.C.; LOPES, E.L.; RONER, M.N.B.; STRINGUINI, J.H.; OLIVEIRA, A.P.A; RUFINO, L.M. Retirada do suplemento micromineral-vitamínico, redução de fósforo inorgânico e adição de fitase em rações de suínos na fase de terminação. Ciência Animal Brasileira, v.9, n.3, p.663-671, 2008.

SANTOS, T.T. Utilização de fitase na suinocultura. Revista Suinocultura
Industrial da Gessulli Agribusiness, v.221, 2009. p.32-38.

SELLE, P.H.; RAVINDRAN, L. Microbial Phytase in poultry nutrition. Animal feed Sciense and technology, v.135, p.1-41, 2007.

SAS Institute. The SAS system for windows. Release 9.0. Cary, 2002.

TEIXEIRA, A.O.; LOPES, D.C.; LOPES, J.B.; VITTI, D.M.S.S.; GOMES, P.C.; ROSTAGNO, H.S.; MOREIRA, J.A.; FELIX, I. Determinação da biodisponibilidade do fósforo de diferentes fontes pela técnica de diluição isotópica, em suínos em crescimento. Revista Brasileira de Zootecnia, v.33, n.5, p.1231-1237, 2004.

VITTI, D.M.S.S.; ROQUE, A.P.; DIAS, R.S.; LOPES, J.B; BUENO, I.C.S.; BUENO, M.S.; NOZELA, E.F. Metabolismo de cálcio em ovinos em crescimento sob suplementação com diferentes fontes de cálcio: aplicação e comparação de dois modelos matemáticos. Revista Brasileira de Zootecnia, v.35, p.2487-2495, 2006.

VITTI, D.M.S.S.; KEBREAB, E. Phosphorus and calcium utilization and requeriments in farm animals. Londres: Cabi International, 2010. $178 \mathrm{p}$.

WOYENGO, T.A; SANDS, J.S.; GUENTER, W.; NYACHOTI, C.M. Nutrient digestibility and performance responses of growing pigs fed phytaseand xylanase-supplemented wheatbased diets. Journal of Animal Science, v.86, p.848-857, 2008.

Data de recebimento: $22 / 03 / 2013$

Data de aprovação: 23/08/2013 